From the analysis of the hydrogen chloride given in column 4, it follows that in both cases more than 90 per cent of the $\mathrm{D}$ had passed over from the hydrogen chloride into the benzene. This has been confirmed by analysing the benzene formed. We have found indications that under the above experimental conditions the reaction proceeds to some extent, even when no $\mathrm{AlCl}_{\mathrm{s}}$ is present; but in this case it goes at a much slower rate.

J. KENNER.

M. Polanyi.

University of Manchester.

P. Szego.

\section{Crystal Structure of Cyanuric Triazide}

IN connexion with the discussion on dipole moments held by the Faraday Society at Oxford in April 1934, Sir William Bragg deseribed ${ }^{1}$ briefly the $^{2}$ results of a research, which I had been making on the structure of cyanuric triazide. A Fourier analysis of the measured X-ray intensities of (hkio) planes showed the three nitrogen atoms of the azide group to be in a straight line ${ }^{2}$. Details of the research were promised later and were held up for an absolute intensity determination to be made. The calculations are now completed and will, I hope, be published soon.

Mr. E. W. Hughes has now published ${ }^{3}$ a structure which resembles mine, but differs from it in certain important features. He shows the azide group as departing from linearity by $15^{\circ}$, while $I$ find that any departure from the straight line could not exceed $3^{\circ}$ or $4^{\circ}$. The distances between the centres of the atoms in the cyanuric ring he finds to be all equal, thus indicating an oscillating double bond as in benzene. I find these distances alternately larger and smaller, corresponding with fixed single and double bonds respectively. The inter-atomic distances which I find are not in complete agreement with his. Mr. Hughes's estimates of the intensity of $X$-ray reflections were made by eye and $I$ cannot think this a sufficiently safe or accurate method for the purpose. My measurements were made by means of a Robinson photometer and put on an absolute scale by the accurate method of the ionisation chamber.

Davy Faraday Laboratory, Royal Institution, W.1.

1 NATURE, 134, 138 ; 1934.

Trans. Far. Soc., 30, 826; 1934.

s. Chem. Phys., 1; 1935 .

\section{Ellie KnagGs.}

\section{Spectra and Latent Energy in Flame Gases}

IN a recent letter on the above subject, Prof. W. T. David $^{1}$ points out that after flame has travelled through an inflammable gaseous mixture, the gases remaining emit luminous (visible and ultra-violet) radiation for a considerable period of time if their temperature is kept up. In an investigation carried out at the United States Bureau of Standards, accounts of which have already appeared $2,3,4$, evidence of prolonged emission in the infra-red was obtained from observations of flame in the cylinder of an engine delivering power.

Infra-red radiation (to about $11 \mu$ ) was recorded from explosions in a small single cylinder L-head engine, through fluorite windows let into the engine head. The fuels used were benzole, and benzole blended with a low-grade petrol, Observations were made of a small depth of charge perpendicular to the direction of flame travel, so that radiation was successively recorded from unburned charge ahead of the flame front, from the flame front, and from gases remaining behind the flame front. Curves of radiation against crank angle were initially horizontal, rose sharply (at the instant visible flame appeared under the window in use) to a maximum, and then decreased gradually.

From gases under a window adjacent to the sparking plug, radiation from non-knocking explosions reached a maximum slightly before maximum pressure was recorded in the eylinder, and at the same instant visible flame appeared under another window, slightly more than $10 \mathrm{~cm}$. away in the direction of flame travel. (This distance corresponded to $20^{\circ}-25^{\circ}$ of engine crank rotation.)

From gases in the 'knocking zone', radiation from non-knocking explosions continued to rise for $20^{\circ}$ of crank angle after the arrival of visible flame: in knocking explosions visible flame arrived earlier, and a higher maximum radiation was reached, $15^{\circ}$ later as against $20^{\circ}$. For both non-knocking and knocking explosions, maximum pressure in the cylinder preceded maximum radiation.

Later in the cycle, both radiation and pressure curves for knocking explosions were below those for non-knocking, indicating greater loss of energy from the charge involved in the knock.

The fact that radiation through a given window continued to rise for approximately $20^{\circ}$ of crank angle after the arrival of flame under that window was taken as evidence that formation of $\mathrm{H}_{2} \mathrm{O}$ and $\mathrm{CO}_{2}$ molecules continued for at least this period, and probably longer, after inflammation. Some doubt was consequently expressed concerning the assumption, based on oxygen determinations at successive moments during the cycle, that combustion is completed in a narrow flame front ${ }^{5}$.

It may be that, in an engine cylinder, some metastable $\mathrm{H}_{2} \mathrm{O}$ and $\mathrm{CO}_{2}$ molecules are formed, which then part with their latent energy, either communicating it to neighbouring molecules or emitting radiation on the wave-lengths characteristic of $\mathrm{H}_{2} \mathrm{O}$ and $\mathrm{CO}_{2}$. This would make it easier to reconcile the $20^{\circ}$ lag between the appearance of flame and the attainment of maximum radiation in the infra-red, with the shorter period required for combustion to be completed in a narrow flame front. It is also possible that the phenomenon of fuel-knock may be connected with the proportion of metastable molecules formed during combustion.

7, Sefton Avenue, SydNey SteEle.

Widnes, Lancs. Dec. 9.

1 NATURE, 134, 663; 1934

Steele, NATURE, 128, 185-6; 1931

3 Steele, Ind. Eng. Chem., 25, 388-93 ; 1933

Marvin, Caldwell and Steele, National Advisory Committee for Aeronautics, Technical Report No. 486; 1934.

5 Withrow, Lovell and Boyd, Ind. Eng. Chem., 22, 945; 1930.

\section{Diamagnetism of Light and Heavy Water}

THE molecular diamagnetism of light water, $12 \cdot 97$, has been closely approached in the values hitherto published for heavy water: $12 \cdot 90^{1}$ and $12 \cdot 76^{2}$. A coincidence has been observed in this department by J. H. Cruickshank, using a Curie-Chéneveau magnetic balance: the molecular diamagnetism of heavy water was $12 \cdot 96 \pm 0 \cdot 02$. Additional measurements 